Western University

Scholarship@Western

2015

The enactment of professional learning policies: performativity and multiple ontologies

Augusto Riveros

Western University, gus.riveros@uwo.ca

Melody Viczko

Western University

Follow this and additional works at: https://ir.lib.uwo.ca/edupub

Part of the Education Commons

Citation of this paper:

Riveros, A., \& Viczko, M. (2015). The enactment of professional learning policies: Performativity and multiple ontologies. Discourse: Studies in the cultural politics of education, 36(4), 533-547 DOI: 10.1080/ 01596306.2015 .980492 


\title{
The enactment of professional learning policies: performativity and multiple ontologies
}

\author{
Augusto Riveros* and Melody Viczko
}

\author{
Both of Western University, Ontario, Canada
}

\begin{abstract}
While teacher learning has become a locus of school reform across many international settings, there is relatively little examination of the idiosyncratic ways in which policy discourses on teacher learning are enacted in schools. In this paper, we aim to investigate how these policy discourses are translated and configured into practices and thus, enacted into concrete realities. Using the conceptual notion of multiple ontologies, we argue that teacher learning is actualized in a multiplicity of socio-material entanglements, not as a single reality, but as a multiplicity of realities that coexist, simultaneously, in the mesh of assemblages that we call 'school'. In this study, we describe and trace how particular socio-material configurations of teacher learning produce concrete realities of practice that mobilize and generate specific networked effects. We conclude that the postulation of multiple ontologies of teacher learning prompts a shift in how policy makers could conceive of and develop strategies aimed at transforming teaching practices.
\end{abstract}

Keywords: performativity, educational policy, teacher learning, sociomaterial, ANT, enactment

\section{Introduction}

Discourses on school reform have positioned teacher learning as a key mechanism for educational change and subsequently, professional development has entered the agenda of educational policy makers in several jurisdictions around the globe (Borko, 2004). The perceived need to align teaching practices with the goals of reform has given visibility to a number of contradictions and tensions between the realities of teaching practices and the realities of educational reform (Hodkinson \& Hodkinson, 2005). One of such tensions was explored through an examination of the idiosyncratic ways in which a policy on professional development was enacted in a school in rural Alberta in Canada (Riveros \& Viczko, 2012; Viczko, 2009). In this paper, we propose that these different ways to enact learning suggest the existence of multiple ontologies of teacher learning in schools. In particular, we argue that these realities of teacher learning emerge through the performances of the different actors, human and nonhuman, that collide to articulate material contexts of practice.

We suggest that if we want to understand the intricacies of school reform, we require an account of the ways in which policy initiatives are enacted in the school. This requires an account of the ways in which teacher learning is configured as a relational effect, tied to the performances of diverse school actors, humans and non-

\footnotetext{
* Corresponding author: mviczko@uwo.ca
} 
humans. In this paper, we note that teacher learning in schools is not performed as a single event that occurs in a unique scenario, but instead, we observe that learning is ontologically diverse. The multiple ways in which teacher learning is performed suggest the existence of simultaneous enactments of teacher learning that coexist in schools.

Teacher learning is the concern of many policy initiatives in Canada, as it is included as a priority in many provincial, jurisdictional, and school-level policies (Riveros, Newton, \& Burgess, 2012). Many of these policies have echoed calls in the literature for including a more active role for teachers in the processes of professional development. For example, Wilson and Berne (1999) have indicated that professional learning should 'not be bound and delivered but rather activated' (p. 194, Italics in original). This suggests that teachers must be seen as active participants in policy initiatives aimed to promote in-service learning instead of passive receivers of information. However, we argue that the idea that teacher learning must be 'activated' does not address how learning is enacted in the school, that is, how the learning of teachers is constituted as a reality. Conceptualizing teachers' learning as a process that must be 'activated' implies that learning by teachers in schools still depends on the active intervention of powerful actors in control of the learning process, and those actors are not necessarily the teachers. We want to reject conceptualizations of teacher learning that tend to locate learning in a particular space or reduce it to a psychological process that occurs in particular individuals. Instead, we propose that teacher learning is configured in emergent socio-material assemblages that are ontologically diverse and include multiple human and non-human actors. In this paper, we adopt the position that we can study the ontology of teacher learning through policy analysis that considers how the policies on professional development are enacted. In doing so, we draw upon Actor Network Theory (ANT) to focus on the socio-materiality of teacher learning in order to examine how policies on professional development are translated into concrete realities.

We offer a few caveats before we proceed. First, our purpose in this paper is to advance a conceptual consideration for the nature of teacher professional learning in order to engage academic conversations about the future of educational research in this area. While empirical data are drawn on in this paper to give examples of ways in which teachers perform professional learning through both discursive and material means, our goal is to theorize the socio-material aspects of professional learning, that is, the performed realities of professional learning, by enrolling ANT into the network of educational research. By doing so, we hope to appeal to broader conversations about the ways in which policies emerge in practice in schools.

Second, in this paper, we use the term 'teacher learning' along with the more traditional moniker of 'professional learning'. In doing this, we want to shed some light on the use of a somewhat controversial terminology (Dall'Alba \& Sandberg, 2006; Nicoll \& Edwards, 2012; Popkewitz, 1994; Stronach et al., 2002). We suggest the traditional emphasis placed on the 'professional' aspects of teacher learning tends to privilege an idealistic image of teachers and their learning (Dall'Alba, 2009; Riveros \& Viczko, 2012). This idealization works to obscure the multiple ways in which teacher learning is configured in the school. Indeed, current discourses of school reform have placed teachers and their learning as instrumental to achieve the goals of the school reform movement (Riveros, 2012; Riveros \& Viczko, 2012). The appeal to 'professionalism' in school reform discourses tends to locate learning processes in idealized subjectivities: the 'professional' is presented as the authoritative agent of change in schools and he/she is reintroduced as the site where 
reform efforts ought to be focused (Popkewitz, 1994; Stronach et al., 2012). We argue that such an instrumentalist characterization of teachers' identities obscures the relational nature of teacher learning. Mindful of the controversies and difficulties surrounding the conventional use of 'professional', in this paper we use the term 'professional' following Dall' Alba's (2009) characterization of professional ways of being. She argued that being professional is a process of becoming:

Contrary to what prevalent models of professional development would have us believe, this process is unlikely to occur in a predetermined or linear sequence (e.g. as proposed by Benner, 1984; Dreyfus \& Dreyfus, 1986) but, rather, to follow a range of possible development trajectories ... This unfolding is open-ended and always incomplete. (Dall' Alba, 2009, p. 43)

Adopting professional ways of being means to be immersed in practices that are changing and dynamic. Learning, in this sense, includes embodied processes that are fluid, situated and interconnected, as opposed to static, individualistic and instrumental to the goals of school reform. Furthermore, we recognize that an attempt to define the 'professional' dimension of teacher learning requires a critical discussion of issues of knowledge, expertise, power and practice that are beyond the scope of this paper.

We propose that a study of the ways in which teacher learning is configured in the multiple realities of practice would present a challenge to the instrumentalist discourses embedded in contemporary school reform. In order to support this claim, we argue that the notion of policy enactment (Ball, Maguire \& Braun, 2012; Maguire, Ball \& Braun, this issue) offers a situated and context-sensitive account of the idiosyncratic ways in which educational policy is translated in schools. In particular, we contextualize the saliency of examining policy enactment by reflecting on data collected in a study (Viczko, 2009) that examined how a policy on professional learning was enacted in a rural school in Alberta, Canada. We note that these policies were enacted in networked interactions that included human and non-human actors (Riveros \& Viczko, 2012). The resultant practices revealed that teacher learning was not a unique event circumscribed to a specific scenario of 'professional learning', but a multiplicity of practices that enacted multiple realities. In our analysis of selected examples from Viczko's (2009) study, we describe how there is not one reality of teacher learning but multiple realities - multiple 'teacher learnings' that are enacted as relational effects of networked interactions. We echo Mol's $(1999,2003)$ call for an ontological politics by asking: What privileges some forms of teacher learning over others? How is this selection made? How is this selection legitimized? Our analysis suggests that when professional learning is conceived of in its material multiplicity, that is, the diverse ways in which the material realities are performed in practice, we are better suited to understand the social and material dimensions of how educational policy is translated into concrete realities in the classroom.

\section{Enacting educational policy}

Policy has been traditionally understood as a social change mechanism intended to modify people's behaviours in order to achieve certain desired goals (Shore \& Wright, 2011). This rationalist approach to policy processes includes a number of steps or stages such as problem definition, design, implementation and evaluation (Rizvi \& Lingard, 2010). The underlying assumption is that policy is a 'problem-solving' mechanism, an instrument of social change (Bacchi, 1999; Wagner, 2007). However, 
this traditional understanding of policy overlooked the idiosyncratic ways in which policy is put into practice. Highlighting a shift towards focusing on the enactment of policy, recent work by Ball, Maguire and Braun (2012), reporting on a study on the enactment of secondary school policies, offered a different picture. One in which policy is brought into existence in complex ways. These scholars showed that policy texts are recontextualized, translated, and adapted in the school. They revealed the creative ways in which policy texts are transformed into practices.

Similarly, Nielsen (2011) looked at a case of conflicting subjectivities between 'customer' and 'co-owner' of a group of Chinese international students studying at a Danish university. The focus in this study was to use an ethnographic approach to policy analysis to look at how " "peopling" policy with multi-dimensional actors whose subjectivities are created in the intersections or interactions' (pp. 69-70) shows the emergence of policy processes. Nielsen drew upon the work of Actor Network Theory scholars Latour $(1999,2005)$ and Law (2009) to argue for a need to pay attention to policy processes as appropriation, whereby policy is seen as a series of translations in which ideas and technologies are transformed when they circulate in institutional contexts. By looking at the conflict between the subjectivities of student as consumer and student as co-owner that emerged through the various interactions with policies, agencies and material relations, Nielsen (2011) described the multidimensional and interconnected assemblage of actors involved in enacting policy. Furthermore, Nielsen argued that such a study calls attention to how links between policy and subjectivity are enacted in the everyday lives of actors as 'a multiplicity of agencies populates the world' (p. 83). The significance of Nielsen's work is the shifting of focus from a linear, rational and instrumental process of policy to one of translation and recontextualization by social actors.

Highlighting the political dimension of policy processes, Shore and Wright (2011) conceptualized policy as a scenario of political contestation, bringing political processes of policy to the fore of the analysis. In their account, actors bring a wide range of resources to the political arena in order to make their discourse prevail. The resources drawn by political actors are both discursive and non-discursive, which means that in order to legitimate their voices, actors construct and contribute to different arrangements or networks constituted by people and objects, thus the policy scenario is constituted by numerous socio-material arrangements that generate contexts of action, deliberation and further practice. This picture of policy processes offered by Shore and Wright counters traditional understandings of policy as a linear, mechanistic and hierarchical processes that fail to recognize the way policy is enacted in the socio-material assemblages that take place in schools.

\section{Analysing policy enactments with Actor Network Theory}

ANT focuses on the heterogeneous nature of networks as nodes or links of messy negotiations, conflicts and contestations through which stability and order seem to emerge (Fenwick, 2010; Nespor, 2004). That is, in networks, certain kinds of materials and people are assembled and translated to become aligned. By 'assembled' we mean put together in heterogeneous networks of human and non-human entities and by 'translated' we mean the process that happens when things connect, changing one another and forming links (Latour, 1986). While diffusion is used in many institutional theories to explain the movement of an object through space and time, the notion of translation 'emphasizes the changes that occur in meanings and 
interpretations as a physical or social object moves through a network' (Lawrence \& Suddaby, 2006, p. 67).

According to Law (1992), translation is the process 'which generates ordering effects, such as devices, agents, institutions, or organizations' (p. 366). Law (2009) also indicated that the research focus of ANT is to 'explore and characterize the webs and the practices that carry them ... [describing] the enactment of materially and discursively heterogeneous relations that produce and reshuffle all kinds of actors' (Law, 2009, p. 141). For example, Hamilton (2011) drew upon ANT to explore how a standardized individual learning plan (ILP) that was intended as a formative assessment tool was translated into an administrative instrument for measurement and quality assurance. Teachers and administrators acted to incorporate the tool into their practices but the introduction of different formats to track the initiative, and the additional paperwork to synchronize the adoption of the tool among teachers, translated the ILP into a set of accountability practices that diverged from the initial goal of the policy, which was to provide a literacy self-assessment tool for individuals.

Similarly, Nespor (2004) investigated how tests of student achievement as policy artefacts participated in shaping educational practices in schools. Teaching and learning processes were translated into test categories that allowed for certain types of measurement that triggered the emergence of particular social and material arrangements in the school. That is, teaching and learning spaces were ordered in ways that facilitated the enactment of the testing regime. New hierarchies, roles and identities appeared as a result of the material re-ordering of the school.

Simultaneously, these arrangements validated specific forms of knowledge in detriment of other forms of knowledge. Indeed, policies on high-stakes testing 'mobilize a whole series of events and people to align with its forms: administrators force curricula to conform to the test's demands, teachers drill classes in test preparation, remedial classes are arranged to improve students' test achievements' (Fenwick, 2010, p. 123). Networks of human and non-human actors assemble to respond to the policy. This explains why policy enactment differs form school to school.

Analysing policy enactments with Actor Network Theory requires the adoption of an ontological strategy as opposed to an epistemological strategy. Law and Singleton (2005) distinguished between these strategies to study objects. The epistemological strategy requires seeing objects through a particular perspective. Multiple perspectives imply multiple descriptions of a single object, descriptions that can conflict or contradict each other. The ontological strategy moves from 'thinking about multiple interpretations of objects ... to think about multiple objects themselves' (p. 334). Law and Singleton noted that realities are 'enacted into being' (p. 334) through the actors' practices. They suggested that the differences between objects must be understood ontologically, in their socio-material relations, highlighting how entities come into being, and not just epistemologically, that is, how objects are represented or interpreted by subjects in their consciousness. An entity is enacted as a reality through the intricate interactions of other entities and practices. One implication of this is that objects are brought to presence in multiple ways: different sets of practices and material relations may enact an object in multiple ways.

Mol (1999) argued that objects are enacted into existence as relational effects of networks constituted by other objects, practices and people. Cordella and Shaikh (2006) argued that ANT 'introduces a new way of conceptualising the understanding of reality' (Cordella \& Shaikh, 2006, p. 14), in that a relational ontology theorizes a becoming of entities through relations, through interactions between actors. Looking 
at the relationality of entities suggests we are not just considering the connections between things that already exist but rather seeking to understand how relationality 'actually configures ontologies' (Fenwick, 2010, p. 119). Reality, according to Mol (1999), is not stable, given, or universal. She characterized reality as 'historically, culturally and materially located' (p. 75) and argued that " "the real" is implicated by the "political" and vice versa' (p. 74). This mutual implication suggests that reality is enacted and performed by actors and objects interacting in complex assemblages. That is, reality is multiple and its multiplicity stems from the various networks of actors and objects that enact multiple and sometimes contradictory contexts of practice.

A stark example of how networked assemblages of human and non-human entities enact objects into reality was presented in Law and Singleton's (2005) study of the treatment of Alcoholic Liver Disease (ALD). They found that the actual object of the disease, the damage of the liver, was enacted differently in the hospital, the substance abuse centre, and the general practitioner's office.

In the hospital, it is a lethal condition that implies abstinence. In the substance abuse centre, it is a problem that implies regulation and control. In the GP's surgery, it is a reality that is better than hard drugs. (2005, p. 347)

Additional to these different understandings of what is the object of ALD, the diagnosis, the treatment, and the treatment effects were different in the community treatment centre, the hospital and the physician's office. This incongruence is particularly dramatic because modern evidence-based treatments in medicine operate under the assumption that a disease is a 'singular, distinct and identifiable object' (Fenwick, 2010).

Mol (1999) offered an example of ontological multiplicity relative to practices in the case of anaemia. She identified at least three ways in which anaemia is performed. First, there is a clinical performance, in the doctor's office, in which the doctor examines the patient for visible symptoms (e.g. white eyelids, dizziness). Second, there is a statistical performance, where a blood sample taken from the patient is tested for haemoglobin levels and the levels are contrasted against statistical data. If the sample's levels are lower than the standard levels, then the patient is diagnosed with anaemia. Third, there is a pathophysiological performance, in which the patient's blood is tested to find if, in that particular patient, the haemoglobin levels are enough to transport oxygen through the body. If the levels are low then the patient is diagnosed with anaemia (Mol, 1999). Mol noted that in practice these three different performances coexist although they may contradict each other. Indeed, sometimes people do not get dizzy or have white eyelids, but nevertheless their haemoglobin levels fall below the statistical average. Or their haemoglobin levels drop, but not enough to be deviant relative to the statistics, and so on. Cases like anaemia show how different realities coexist to enact particular effects. In some contexts where doctors do not have access to laboratory analysis, the clinical performance of anaemia prevails and subsequent practices ensue, such as particular treatments based on the diagnosis.

What Mol is offering here is a relational ontology, one in which entities are emerging realities enacted in networked interactions. However, multiplicity does not always imply incompatibility: 'what multiplicity entails instead is that, while realities may clash at some points, elsewhere the various performances of an object may collaborate and even depend on one another' (Mol, 1999, p. 83). That is, she asserted that if realities exist as relational effects, then the multiple versions of something that 
exists in the world must also be relational. These realities are not plural perspectives that stand apart from each other. Rather, as Mol reminded us, realities are multiple, relational and situated. In her words, realities 'may follow the other, stand in for the other, and, the most surprising image, one may include the other. This means what is "other" is also within. Alternative realities don't simply co-exist side by side, but are also found inside one another' (Mol, 1999, p. 85). Mol's purpose in focusing on the notion of multiple ontologies is to suggest an ontological politics at play, namely, the idea that

... reality does not precede the mundane practices in which we interact with it, but is rather shaped within these practices. So, the term politics works to underline this active mode, this process of shaping, and the fact that its character is both open ended and contested. (1999, p. 75. Italics in original)

She argued that the postulation of multiple realities suggests that 'there is, or should be a choice between them' (p. 79). An exploration of ontological politics offers insights into the way a particular reality is chosen over multiple options. In exploring how a particular reality is selected, Mol suggested to investigate where are the options situated and what is at stake when the decision is made. In addition, we need to investigate to what extent there are really options and how should the decision be made. These questions are central in an investigation of the enactment of school realities. We consider Mol's conceptualization useful to our investigation into the realities of teacher learning. In our analysis of the interviews and observational data, we asked whether teacher learning was configured in ways that articulated multiple and coexisting realities. We were interested in the practices that emerged as a result of the enactment of particular policies on teacher learning.

In the following section, we engage in a conceptual argument that looks at the ways in which teacher professional learning is brought into practice by briefly illustrating scenarios that emerged from a study that examined teachers' understandings of professional learning policies (Viczko, 2009). While we have detailed the specifics of the research project elsewhere (Riveros \& Viczko, 2012), the scenarios of professional learning elaborated here capture a moment of insight to advance our purposes in this paper related to questioning the ontological manifestations of teacher professional learning in its heterogeneity. Importantly, we do not aim to make claims about the nature of professional learning based on these scenarios, but rather we offer them as examples of the multiplicity in the performances of professional learning.

The examples that we analyse are based on a qualitative study (Viczko, 2009) that examined teachers' understandings of professional learning in a rural school in Alberta, Canada. To provide some background information about that qualitative study, the data were collected over a two-month period involving interviews, focus groups, and researcher journaling. That study adopted a qualitative methodology that allowed for an in-depth exploration of the narratives of the participants as well as a detailed analysis of the observations registered in a field-notes journal. While some studies using ANT focus solely on observational data, our purposes here in this article are to use the insights offered by ANT to reflect on that interview data and researcher journaling to consider 'what things and people do' (Fenwick \& Edwards, 2010, p. 151). As Latour reminds us, 'actors know what they do' (1999, p. 20) and so we have used the data collected in that study as a point of departure to consider policy enactments. In the next section, we want to highlight aspects of professional learning that emerged for us as we considered the ways in which the teachers enacted their 
professional learning reflected in both way they talked about their professional learning and the observations of their teaching.

\section{Classroom practice and professional development meetings: the performed realities of teacher learning}

One aspect of professional learning we want to illuminate is the performative configuration of 'spaces' of professional learning. When we talk about spaces, we are not referring to an inert, passive and transparent background for objects. We understand space as "constituted through the social, with interactions creating social space. Space is then performed or enacted as a recursive relationship between the spatial and the social as relations of power' (McGregor, 2004, p. 351). Conceiving space as performed brings to the fore a whole new set of understandings about the constitution of reality as fluid, dynamic and always becoming, an assemblage of the social and the material. In considering how teachers understood their professional learning, we found that particular performances of space were constituted through workshops and professional development meetings. These performances constituted formal or 'sanctioned' scenarios of professional learning. In these prescribed spaces, organizational resources were mobilized to enrol different human and non-human actors in the enactment of the policy. The mobilization of resources, such as the rearrangement of timetables and rescheduling, were possible as an effect of the administration's capacity to exercise some degree of influence in the social and material arrangements of the school, the effect of which were particular configurations of professional learning. In other words, the administration of the school expanded its capacity to influence teacher learning by playing a role on the way resources were reorganized and learning was enacted.

The enactment of these administrative influences was elaborated in the ways that teachers talked about marked divisions between what they did in prescribed learning spaces and what they did in their teaching practices. For example, one teacher expressed how she would engage in formalized learning events staged by the central school division office during official days that were scheduled. She expressed that she attended these events out of a sense of duty, in the role of being a teacher, to the goals and strategic plans of the school division office or the Ministry of Education.

However, once in her classroom, she would actively return to her personal efforts to improve her practice. Importantly, in her description of the ways she enacted her professional learning was the idea that there are formalized structures, though they did not influence her practice in a way that was meaningful to her. Rather, these formalized administrative social and material arrangements were problematic, in that she felt they were disconnected from her practice. Rather, she preferred opportunities for learning that involved thinking about how to improve her practice of teaching rather than having to 'throw out all the stuff I did before'.

In addition to the formal spaces, different types of professional learning spaces were constituted through some classroom practices. In these spaces, teacher learning was not necessarily circumscribed to the areas prioritized in the meetings and workshops. In the classroom, professional learning emerged at the margins of the administration's sphere of influence. Sometimes enacting forms of professional learning did not reflect the priorities set during the professional development meetings. The teachers, when talking about the ways they learned about their teaching, revealed 
the existence of these alternative scenarios of professional learning. In conversation, many participants indicated that their teaching priorities were predominantly situated in their particular contexts of practice. Many complained that the goals set by the administration's reading of the policy on professional development did not reflect their instructional needs and aspirations. Teachers described these administrative attempts at professional learning to be 'overwhelming', as there were 'too many things' with unrealistic amount of changes 'that were difficult to put into action', according to one teacher. These revelations were later corroborated by observing how the classroom practices enacted forms of teacher learning that prioritized the local context in detriment of the goals set by the administration.

An example of how professional learning was enacted in idiosyncratic ways that privileged the local could be seen in the introduction of artefacts that contributed to the consolidation of classroom practices. For instance, the introduction of a poster as a new instructional tool mobilized specific literacy practices and enrolled different actors together. One of the teachers introduced the poster as a component of an instructional initiative that she found to be realistic in the sense that it could be incorporated with concrete effects in her classroom practices. Professional learning, as a performance, was transformed when the poster entered the classroom.

Another teacher described learning how to use new technological tools in the classroom, such as a computer program to support geography lessons, as a meaningful way to impact his practice. Specifically, he reflected that by taking the time to use this tool in his teaching he began to think differently about how students learned the topic at hand. He talked about how his own learning through his teaching impacted his practice: 'it doesn't have to be something big, but it can be just something that just changes the way you might be doing something a little bit and makes you think'. This teacher described how the new tool was enrolled into the classroom learning as it reoriented how he engaged with his students in the geography lessons. The translation of the technological tool into an interactive teaching lesson was meaningful learning for this teacher.

As a result of these new configurations, new classroom practices emerged and new learning took place. In this case, learning is understood as a practical and embodied engagement in the world, an effect of the re-accommodation of human and non-human assemblages that offers new possibilities, new ways of being (Fenwick \& Edwards, 2010; Law, 2009; Sørensen, 2009). In the following section we offer more details on how these multiple realities of teacher learning were performed into existence.

\section{Enacting teacher learning in socio-material assemblages: ontological politics}

By focusing on the enactment of professional learning policies, we suggest that the heterogeneous nature of teacher learning is brought to the fore. The focus shifts from the teacher as the sole agential actor, so that we begin to notice other actors at play. For instance, by paying attention to artefacts and describing how their presence in the classroom contribute to the emergence of idiosyncratic performances of teacher learning, we recognize that particular enactments of learning take place in the sociomaterial assemblages that are constituted as humans and non-humans are mobilized and put together in networked interconnections. Taking the stance that teacher learning is enacted suggests that we must pay attention to what is performed in 
practice. So, learning does not sit passively waiting to be activated. Rather, it is enacted in the socio-material engagements that constitute the practice of teaching.

Another important insight offered by the study of the enactment of professional learning relates to the particular form of learning that ends up being privileged. Mol (1999) argued that the existence of multiple realities implies the possibility to select between those realities. Furthermore, the selection of one reality over the others suggests the existence of an 'ontological politics' at play. We want to suggest that the capacity to influence the selection of a particular performance of learning is an effect of diverse configurations of power. Performances of teacher learning do not emerge in a vacuum: they are effects of wider entanglements of human and non-human actors. As we noted above, in this school, professional learning was enacted in different spaces: some spaces were formal and prescribed, such as the professional development meetings and workshops, and some other spaces were local and specific to the classroom situation. These performances mutate and actualize as teachers navigate the complexities of their daily lives in the school. For example, in this school, the prescribed performances of professional learning were generally circumscribed to confined spaces and scheduled events, and in many cases, they were not translated into classroom practices. For instance, some teachers pointed out that the school hosted a number of events that were conceived as events for professional learning, but failed to bring about a meaningful contribution to her teaching practices.

These occurrences of teacher learning, influenced by the administration's goals, are as real as the occurrences of learning that take place between the teachers, the students, and the artefacts in the classroom. Indeed, some teachers established a clear distinction between the professional learning that takes place in these formal spaces and the professional learning that occurs, informally, in the classroom practice, outside the prescribed spaces. In the classroom performance, learning takes place as an effect of the configuration and reconfiguration of teaching practices. This performance of professional learning does not necessarily reflect the policy goals of the school, district or province, but reflects specific needs and interests situated in the classroom. We are not suggesting a simple duality of performances here. These performances interact and connect in many cases. Some teachers moved in a fluid back and forth between the prescribed performance and the classroom performance configuring overarching practices that, in some cases, merged these two realities of professional learning. One teacher who participated in workshops organized by the administration explained to us how she experienced this fluid mobility between performances of professional learning. We found one of her comments particularly revealing. We believe it is worth the long quote:

\footnotetext{
I know that we probably don't know off by heart what the division goals are for PD and the provincial goals are for teachers, but I know we've been told them. I know that of course legally we are working within them, but really we're being spoon fed that stuff. Today we're going to work on this because that's part of the division goal, right, so you just do it. And then the next week you go back to your poster. (Teacher)
}

In the workshop, professional learning was oriented to articulate the provincial literacy goals. Participating in these activities gave the teachers a conceptual repertoire to understand the policy documents and discourses coming from the province and the administration. However, many teachers intimated that these newly articulated understandings were not necessarily translated into classroom practices. In the case of the teacher quoted above, her selection of a poster as a key component in the teaching of literacy, at the expense of other components of the same program, 
resulted in the emergence of idiosyncratic practices that emerged thanks to the presence of this particular artefact in the classroom. In this classroom, professional learning was configured as an effect of local circumstances, such as the teacher's assessment of the students' needs, the already established instructional practices and the available resources. The introduction of a poster as a key literacy tool did not necessarily reflect all the goals of the literacy policy, but reflected the particular way in which the actors in the classroom converged to enact the provincial goals on literacy. This is an example of how actors in this school became mobile and inhabited different realities of professional learning that were performed simultaneously.

Following Mol's (1999) insights, the notion of multiple realities implies an ontological politics in which realities become options that can be enacted. The actors in our study were able to participate in the enactment of these different realities; they shifted between performances of professional learning. While there may be numerous motivations for these shifts to occur, we believe these shifts are facilitated or constrained by issues of power and legitimacy within the school. The prescribed enactments of professional learning carry out organizational legitimacy as they are sanctioned by the administration and organized as formal events of professional learning. The capacity to shift away from the prescribed performance and explore different enactments of professional learning could be related to the capacity of the teachers to leverage the risks of stepping out of the norm and incorporate new practices into their classroom performance. A key difference between these two performances of professional learning is that in the annual report to the school board the prescribed performance becomes visible and legitimate, whereas the classroom performance becomes invisible and disappears.

A study of the multiple enactments of professional learning in schools provides valuable insights into the ways school actors configure spaces of resistance and transformation. This is true of other instances of educational reform, for example, Fenwick and Edwards (2010) noted that in the case of curriculum standards, teachers reconfigure policies in contextualizing practices that challenge the idea that reforms are always imposed on school actors:

Standards exist in multiple ontological forms that are performed simultaneously and that, as networks themselves, are continually changing shape. Educators, like other practitioners, are quite used to juggling these shape-shifting forms and their tensions of simultaneity within the high voltage dynamic of everyday commotion. In these ways, ANT highlights the limitations of conventional accounts of standards as globally formed ideals troubled by imperfect local implementation, or as cases of domination and subjugation that require local resistance to topdown exercises of power. (2010, pp. 97-98)

This is an area that requires further interrogation in understanding the multiplicity of ways in which professional learning policies are enacted into different school realities. This avenue of research provides a situated way to understand the various forms of teacher learning that emerge in schools everyday. Our analysis aims to portray teachers, among other human and non-human school actors, as performers that participate in the enactment of school policies in networked associations with other actors and objects.

\section{The materiality of policy and teacher learning}


In our analysis, we were interested in tracing the material manifestations of the policy and in particular, in identifying how the assemblages between human and non-human actors constituted enactments of policies on professional learning. In this regard, Waltz (2006) argued that artefacts in schools are not mere tools that represent human intentions: 'In treating nonhumans as representatives of human ends, their particular contributions are obscured - as are the complex ways in which they interact with humans in the constitution of social events' (p. 56). In ANT terms, humans and nonhumans participate in networked associations with one another, there is no categorical difference between them, and thus no special privilege is granted to humans in the constitution of social reality.

Our findings suggest that these networked associations between humans and nonhumans were constitutive of particular enactments of teacher learning. One case that caught our attention during our analysis included the use of a 'teacher growth plan' and the introduction of a poster that displayed grade-level literacy goals in an elementary classroom. The poster was introduced as part of a literacy-based program that took place in one of the formal spaces of professional learning that we previously described, more specifically, the program included monthly workshops organized by the school district. Although the program comprised other elements and strategies, in this particular classroom, the poster became a significant protagonist in the enactment of the literacy program. Once the poster was incorporated into the classroom, a new range of practices were brought to the fore. For instance, the poster became a central focus of the teacher's professional growth plan. In this school, teachers were required to create and follow a professional development plan that outlined a number of learning goals to be accomplished throughout the school year. The growth plan, which emerges in our analysis as another networked participant in this assemblage, was important in that it provided a sense of direction and contributed to articulate classroom practices that aligned with the goals outlined in the plan.

For the teacher, writing down the goal on her professional growth plan was significant. Namely, the learning goal became something visible: a tangible reminder that she will be evaluated by the administration at the end of the school year. As an artefact that intersects professional learning opportunities and school performance evaluation policy, the current enrolment of personal and individual learning could serve to mask the complexity of activities happening in the school. Furthermore, she commented that 'writing it down' was a way to indicate what was important to her, as opposed to it being 'an unwritten goal that I've had for a quite a few years'. The use of the poster as a goal in the teacher's professional growth plan, allows us to appreciate how professional learning emerges as an effect of socio-material relations that converge to create a particular reality. Learning, in this case, was constituted by the encounter of several actors, humans and non-humans. The particular arrangement that included the teacher, the poster and the growth plan could be traced back to the administration's capacity to influence the way resources circulate in the school.

However, this example also shows how enactments of professional learning are local, reflecting particular idiosyncrasies inhabiting the classroom. This could be noticed in the selection of the goals and the inclusion of the poster in detriment of other strategies and goals available to the teacher. In this case, it is possible to see how the two performed spaces of teacher leaning, the workshops and the classroom, interacted in a continuous back and forth that ultimately informed multiple realities of practice. In conversation, the teacher intimated that the poster used in this specific literacy program better connected her to the curriculum, stating that the program '... is so fabulous for me for teaching. The poster outcomes are so fabulous for me to 
revisit my curriculum often' (interviewed teacher). Here we can see a concrete manifestation of the policy initiative integrated in the network of materials and people that enact a particular policy on professional development. The poster, as a concrete manifestation of the policy, is not just a tool that entered the classroom, it actively contributed to shape the actions and practices of the people around it. The teacher acknowledged the poster's influence in her practices and furthermore declared that due to the possibilities of action afforded by the poster, this particular professional learning initiative was more 'realistic' than other initiatives that could not achieve a material manifestation in the classroom.

The introduction of a new object into the classroom context initiates a series of transformations or translations in which actors transform their own practices as they interact with the new artefact. The realities that are performed in the classroom are thereby transformed by the new socio-material arrangements brought about by the new artefact and the other actors' interactions with the object, and thus, educational policy becomes enacted in the practices of the school actors.

\section{Conclusion}

In this paper we have offered an exploration of the ontological dimensions of professional learning in schools. Based on examples taken from a study that explored the enactment of policies on professional learning in a rural school in Canada (Viczko, 2009), we have suggested that teacher learning not just a cognitive, individualistic process, but a set of complex and performed assemblages that include a multiplicity of networked actors. Furthermore, we argued that these assemblages constitute idiosyncratic spaces of professional learning that produce multiple social realities. Following Mol (1999, 2003), we suggested that professional learning is performed in multiple ways, pointing to the existence of multiple realities of professional learning inhabiting the school. In our analysis, we identified emerging spaces of professional learning where the policies on professional learning are enacted. These enactments of policies on professional learning provide an example of how school actors, human and non-human, bring policy abstractions to concrete realities through networked assemblages. This presents a challenge to the traditional assumption that policy is a production of authoritative individuals that is transferred down the institutional hierarchy only to be 'implemented' by school actors (Colebatch, Hoppe, \& Noordegraaf, 2011). In these instrumentalist narratives, when the implementation does not match the intentions of the policy designers, the resultant practices are casted as errors or resistance. We have shown that the notion of policy enactment (Ball, Maguire \& Braun, 2012) offers a situated and context-sensitive way to talk about the transformations and adaptations of educational policy that overcomes the limitations of the instrumentalist models in policy analysis.

We have highlighted the notion of ontological politics (Mol, 1999) and argued that the ontological dimension of professional learning intersects with its political dimension. This was evidenced in the capacity of the different actors to shift, influence and bridge different performances through practices. Our analysis aimed to shed light on the enactment of policies on professional learning. Actor Network Theory analyses of educational policy enactments show that the complex networks of people and objects that enact educational policies are situated in specific social, cultural and historical contexts. Our aim in bringing this analysis to the professional learning field is to show that when the notion of enactment is invoked, there is a depth 
to the quality of professional learning that better considers the complexity within which the practice of teaching is configured in schools (Riveros \& Viczko, 2012). We believe that these intricacies must be reflected upon when considering and developing strategies aimed at transform teacher learning.

\section{References}

Bacchi, C. (1999). Women, policy and politics: The construction of policy problems. London: Sage.

Ball, S., Maguire, M., \& Braun, A. (2012). How schools do policy: Policy enactments in secondary schools. London: Routledge.

Benner, P. (1984). From novice to expert: Excellence and power in clinical nursing practice. San Francisco: Addison-Wesley.

Borko, H. (2004). Professional development and teacher learning: Mapping the terrain. Educational Researcher, 33(8), 3-15.

Colebatch, H.K., Hoppe, R., \& Noordegraaf, M. (2011). Working for policy. Amsterdam: Amsterdam University Press.

Cordella, A., \& Shaikh, M. (2006). From epistemology to ontology: Challenging the constructed 'truth' of ANT (Working Paper Series, No. 143). London: London School of Economics and Political Science. Retrieved from http://is2.lse.ac.uk/wp/pdf/WP143.PDF

Dall'Alba, G. (2009). Learning professional ways of being: Ambiguities of becoming. Educational Philosophy and Theory, 41(1), 34-45.

Dall'Alba, G. \& Sandberg, J. (2006). Unveiling professional development: A critical review of stage models. Review of Educational Research, 76(3), 383-412.

Dreyfus, H.L. \& Dreyfus, S.E. (1986). Mind over machine: The power of human intuition and expertise in the era of the computer. New York: Free Press.

Fenwick, T. (2010). Un(Doing) standards in education with actor-network theory. Journal of Education Policy, 25(2), 117-133. doi: 10.1080/02680930903314277

Fenwick, T., \& Edwards, R. (2010). Actor-network theory in education. London: Routledge.

Hamilton, M. (2011). Unruly practice: What a sociology of translation can offer to educational policy analysis. Educational Philosophy and Theory, 43(1), 55-75.

Hodkinson, H., \& Hodkinson, P. (2005). Improving school teachers' workplace learning. Research Papers in Education, 20(2), 109-131.

Latour, B. (1986). The powers of association. In J. Law (Ed.), Power, action and belief: A new sociology of knowledge? (pp. 264-280). London: Routledge.

Latour, B. (1999). On recalling ANT. In J. Law, \& J. Hassard (Eds.), Actor network and after (pp. 1525). Oxford: Blackwell.

Latour, B. (2005). Reassembling the social: An introduction to actor-network theory. Oxford: Oxford University Press.

Law, J. (1992). Notes on the theory of the actor-network: Ordering, strategy, and heterogeneity. Systems Practice, 5(4), 379-393.

Law, J. (2009). Actor network theory and material semiotics. In B.S. Turner (Ed.), The new Blackwell companion to social theory ( $3^{\text {rd }}$ ed.) (pp. 141-158). Chichester, UK: Blackwell.

Law, J., \& Singleton, V. (2005). Object lessons. Organization, 12(3), 331-355.

Lawrence, T., \& Suddaby, R. (2006). Institutions and institutional work. In S. Clegg, C. Hardy, W.R. Nord, \& T. Lawrence (Eds.), Handbook of organization studies (pp. 215-254). London: Sage. 
McGregor, J. (2004). Spatiality and the place of the material in schools. Pedagogy, Culture and Society, 12(3), 347-372.

Mol, A. (1999). Ontological politics. In J. Law, \& J. Hassard (Eds.), Actor network theory and after (pp. 74-89). Oxford: Blackwell.

Mol, A. (2003). The body multiple: Ontology in medical practice. Durham, NC: Duke University Press.

Nicoll, K., \& Edwards, R. (2012). Positioning adult educators in discourses of professional development. Studies in Continuing Education, 34(3), 233-249.

Nielsen, G. B. (2011). Peopling policy: On conflicting subjectivities of fee-paying students. In C. Shore, S. Wright, \& D. Pero (Eds.), Policy worlds: Anthropology and the analysis of contemporary power (pp. 68-85). New York: Berghahn.

Nespor, J. (2004). Education scale-making. Pedagogy, Culture and Society, 12(3), 309-326.

Popkewitz, T.S. (1994). Professionalization in teaching and teacher education: Some notes on its history, ideology, and potential. Teaching and Teacher Education: An International Journal of Research and Studies, 10(1), 1-14.

Riveros, A. (2012). Beyond collaboration: Embodied teacher learning and the discourse of collaboration in school reform. Studies in Philosophy and Education, 31(6), 603-612.

Riveros, A., \& Viczko, M. (2012). Professional knowledge 'from the field': Enacting professional learning in the contexts of practice. McGill Journal of Education, 47(1), 37-52.

Riveros, A., Newton, P., \& Burgess, D. (2012). A situated account of teacher agency and learning: Critical reflections on professional learning communities. Canadian Journal of Education. 35(1), 202-216.

Rizvi, F., \& Lingard, B. (2010). Globalizing policy field. London: Routledge.

Shore, C., \& Wright, S. (2011). Conceptualising policy: Technologies of governance and the politics of visibility. In C. Shore, S. Wright, \& D. Pero (Eds.), Policy worlds: Anthropology and the analysis of contemporary power (pp. 1-26). New York: Berghahn.

Sørensen, E. (2009). The materiality of learning: Technology and knowledge in educational practice. Cambridge: Cambridge University Press.

Stronach, I., Corbin, B., McNamara, O., Stark, S., \& Warne, T. (2002). Towards an uncertain politics of professionalism: Teacher and nurse identities in flux. Journal of Education Policy, 17(1) 109-138.

Viczko, M. (2009). A comparative case study of teacher professional learning in England and Alberta. Unpublished masters thesis, University of Alberta, Edmonton, Alberta, Canada.

Wagner, P. (2007). Public policy, social sciences and the state: A historical perspective. In F. Fischer, G.J. Miller, \& S. Sidney (Eds.), Handbook of public policy analysis: Theory, politics and methods (pp. 63-78). Boca Raton, FL: CRC Press.

Waltz, S. (2006). Nonhumans unbound: Actor-Network Theory and the reconsideration of 'things' in educational foundations. Educational Foundations, 20(3-4), 51-68.

Wilson, S.M., \& Berne, J. (1999). Teacher learning and the acquisition of professional knowledge: An examination of research on contemporary professional development. Review of Research in Education, 24(1999), 173-209. 